\title{
An experimental-numerical method for estimating heat transfer in a Bridgman furnace
}

\author{
Robin P. Mooney ${ }^{1}$, Shaun McFadden ${ }^{1}$, Zuzana Gabalcová ${ }^{2}$ Juraj Lapin ${ }^{2}$ \\ ${ }^{1}$ Trinity College Dublin, Dublin 2, Ireland \\ ${ }^{2}$ Institute of Materials and Machine Mechanics, Slovak Academy of Sciences, Račianska 75, \\ 83102 Bratislava, Slovak Republic
}

Corresponding author: $\quad$ Tel.: $\quad+35318963431 \quad$ Fax: $\quad+35316795554$

E-mail address: $\quad$ mooneyrp@tcd.ie (R.P. Mooney)

\begin{abstract}
Direct measurement of heat flux and heat transfer coefficients in a Bridgman furnace is not always possible using traditional methods. This study characterised a vertical tubular Bridgman furnace using experimental data so that the estimated heat flux and heat transfer coefficients may be used in simulations of future experiments using the same furnace. An experimental-numerical method is presented where a discrete proportional integral derivative controller manipulates the radial heat flux in a front tracking solidification model so that the output temperature profile matches experimental data. The method is applicable for other experimentalists and modellers and its usefulness is demonstrated by example.
\end{abstract}

\section{Highlights}

- A combined experimental-numerical method to estimate heat flux and heat transfer coefficients in a Bridgman furnace is outlined in detail.

- The inverse heat transfer problem is solved using a discrete proportional integral derivative controller in series with a front tracking solidification model.

- The usefulness of the method is demonstrated by example.

\section{Keywords}

Bridgman furnace; heat transfer coefficient; experimental-numerical method; inverse heat transfer; front tracking 


\section{Introduction}

The 'Bridgman Furnace' takes its name from the 1946 Nobel Prize winning Physicist; Percy W. Bridgman. In the 1920's, Bridgman developed a technique of lowering a cylindrical crucible at a fixed velocity along the axis of a vertical tubular furnace, held at a fixed temperature, to produce single crystal materials [1]. This technique was later modified by Donald C. Stockbarger in the 1930's to produce large single crystals of lithium fluoride [2], where a high temperature gradient was required for successful growth. To achieve higher gradients, a second tubular heat sink was employed, separated from the furnace heater by a thin annular baffle. The resulting solidification procedure is known as the BridgmanStockbarger technique, Bridgman solidification, or the Bridgman method.

Many variations of the original set-up have since been developed; however, the principle of operation has remained the same. The key advantage of this method is that solidification can be performed in a controlled manner, by changing either the temperature gradient or the crucible velocity (known as the pulling rate). The method is widely used in research and industry. For example, in research, Bridgman solidification is used to investigate interfacial characteristics in the growth of semiconductor compounds [3], and in industry it is used to cast high pressure turbine blades as a single crystal [4].

A schematic of a typical Bridgman furnace and the sample material temperature profile is shown in Fig. 1. The sample solidifies as the crucible is lowered (or pulled) through the furnace at some velocity $u$. In pure materials, a planar solid-liquid interface will normally form [5]. In alloys, the material will typically form a mushy zone [6] (a mixture of solid and liquid), and a mush-liquid interface, as shown in Fig. 1. The temperature gradient in the sample can be varied by changing the baffle thickness $L_{A}$, or by varying the heater and heat sink temperatures.

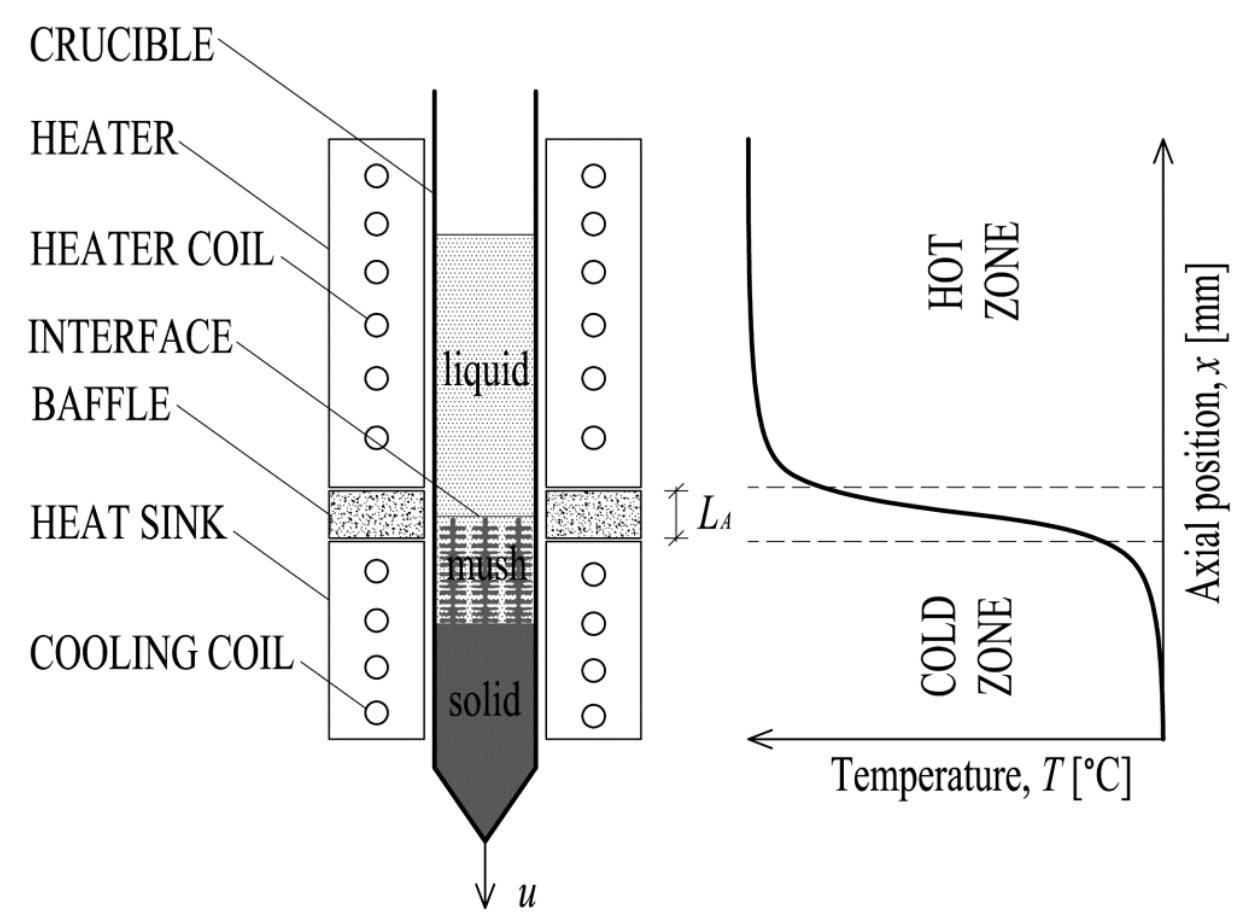

Fig. 1 Schematic of a typical Bridgman furnace and temperature profile. 
Determining the furnace heat transfer coefficients using traditional techniques can be time consuming and difficult to do accurately. The calculation depends on furnace and sample geometry, the sample properties, the crucible properties, and the furnace's atmospheric conditions. It is necessary for experimentalists to know the heat transfer coefficient of their furnace so that they can accurately estimate the true temperature gradient and temperature profile within a test sample.

The material of interest, in this study, is a titanium aluminide multi-component alloy with nominal composition; Ti-44.5Al-4.5Nb-0.2C-0.2B (at.\%). This alloy, and variations of it [7], have emerged as candidates to replace nickel superalloys in the aerospace industry on account of their very low density and excellent mechanical properties at high temperature. Detailed studies [8] have been proposed that will investigate the relationship between the solidification conditions and the resulting microstructure for similar titanium aluminide alloys. The columnar to equiaxed transition (CET) in the microstructure is of particular interest.

An investigation into the microstructure development was deemed to be beyond the scope of this paper. This article is concerned with the characterisation of the heat transfer conditions in the Bridgman furnace that will be used in future studies to investigate solidification of the titanium aluminide multi-component alloy. Hence, this study is a prerequisite for other key experiments that will be conducted in the same Bridgman furnace. The method outlined here is useful as it may be applied to other furnaces.

\subsection{Literature review}

An experimental procedure was outlined by Banan et al. [9] where an average heat transfer coefficient between a sample and the surrounding furnace was estimated using a lumped capacity cooling model. An isothermal sample was suddenly moved to a hotter part of the furnace and the thermal history was recorded.

An experimental study by Rosch et al. [10] combined radiation and convection heat fluxes to estimate an overall heat transfer coefficient in a Bridgman furnace. The radiation heat flux was linearised with respect to temperature difference as,

$$
T_{f}^{4}-T_{m}^{4} \approx 4 T_{a v}^{3}\left(T_{f}-T_{m}\right),
$$

where, $T_{f}$ was the furnace temperature and $T_{m}$ was the surface temperature of the muffle tube containing the ampoule, and $T_{a v}$ was their average. This approximation produced an error of less than 2 percent provided that $T_{f} / T_{m}$ and $T_{m} / T_{f}$ was less than 4/3. Ultimately, Rosch et al. merged the $4 T_{a v}{ }^{3}$ into the overall combined heat transfer coefficient. Rosch subjected the sample to additional heating - within the operating furnace - using an electrical heating coil wrapped around the crucible; thus, creating a known temperature difference between the sample and furnace heater. The work was extended [11] to estimate convection coefficients in different gas environments, and emissivities for different coil sleeve materials. Neither of these studies treat the heat transfer coefficient as a function of axial position, that is, fixed values were used for the heat transfer coefficient in the hot and cold zones. However, both studies concluded that the overall heat transfer coefficient is non-linear (a function of temperature cubed) at higher temperatures due to dominant radiation heat transfer. 
A numerical study by Bartholomew and Hellawell [12] looked at changes in growth rate and temperature gradient where the radiation heat transfer incorporated a view factor to account for a typical furnace geometry. Separate values for liquid and solid thermal conductivity were used.

Several analytical studies [13][14][15], concerned with interface shape and interface velocity during growth of crystalline materials, used a fixed value for heat transfer coefficient to specify their boundary conditions. However, it was noted that the heat transfer coefficient should increase at high temperatures due to increased radiative effects.

\subsection{Aims and objectives}

The following aims and objectives were identified:

1. To estimate the heat flux at the ends of the cylindrical sample.

2. To estimate the heat transfer coefficient at the ends of the cylindrical sample.

3. To estimate the heat flux at the circumference of the sample as a function of axial position.

4. To estimate the heat transfer coefficient at the circumference of the crucible as a function of axial position.

\subsection{Article summary and structure}

A combined experimental-numerical approach was adopted. An experimental procedure was initially performed where steady-state temperature measurements in the sample were taken along its centreline, for different furnace temperatures. A numerical modelling approach was developed to process the experimental data. The model solved for the heat flux at the circumference of the sample and in the crucible, and hence the heat transfer coefficient at the circumference of the crucible as a function of axial position.

In what follows, section 2, details of the experimental method (apparatus and procedure) are explained, followed by details of the mathematical model used, the method for calculating heat transfer coefficients, and the method for numerical implementation of the mathematical model. The simulation input parameters are given in section 3. Section 4 contains the simulation results. Section 5 discusses the results, and finally section 6 states the conclusions from the study.

\section{Methodology}

\subsection{Experimental method}

The procedure for characterising the furnace began with an experimental analysis.

\subsubsection{The experiment apparatus}

The experiments were carried out using a vertical Bridgman furnace, as shown schematically in Fig. 2. The furnace, fully described elsewhere [16], consisted of a cold 
formed smooth molybdenum resistance heating element in the hot zone. The cylindrical heating element had a length of $300 \mathrm{~mm}$ and inside diameter of $33 \mathrm{~mm}$. The space between the hot and cold zones was $7 \mathrm{~mm}$, made up by a $5 \mathrm{~mm}$ thick annular aluminium oxide baffle and a $2 \mathrm{~mm}$ gap on the hot side. The cold zone heat sink consisted of a cylindrical water cooled 'crystalliser' with inside diameter of $16 \mathrm{~mm}$.

The sample was a $170 \mathrm{~mm}$ long rod of titanium aluminide, with a diameter of $10 \mathrm{~mm}$. The sample was contained in a high purity yttrium oxide $\left(\mathrm{Y}_{2} \mathrm{O}_{3}\right)$, crucible with outside diameter of $15 \mathrm{~mm}$, and a wall thickness of $2.5 \mathrm{~mm}$. A moveable thermocouple was located in the longitudinal axis of the sample, contained in a protective closed-end alumina tube, with inside and outside diameters of $3 \mathrm{~mm}$ and $5 \mathrm{~mm}$, respectively. The tube was plasma sprayed with a layer of yttrium oxide to minimise reaction between the tube and the melt. The thermocouple was free to traverse in the axial direction of the crucible. The alumina tube was fixed and contained air at standard atmospheric pressure. The open end of the tube was closed with a sealant.

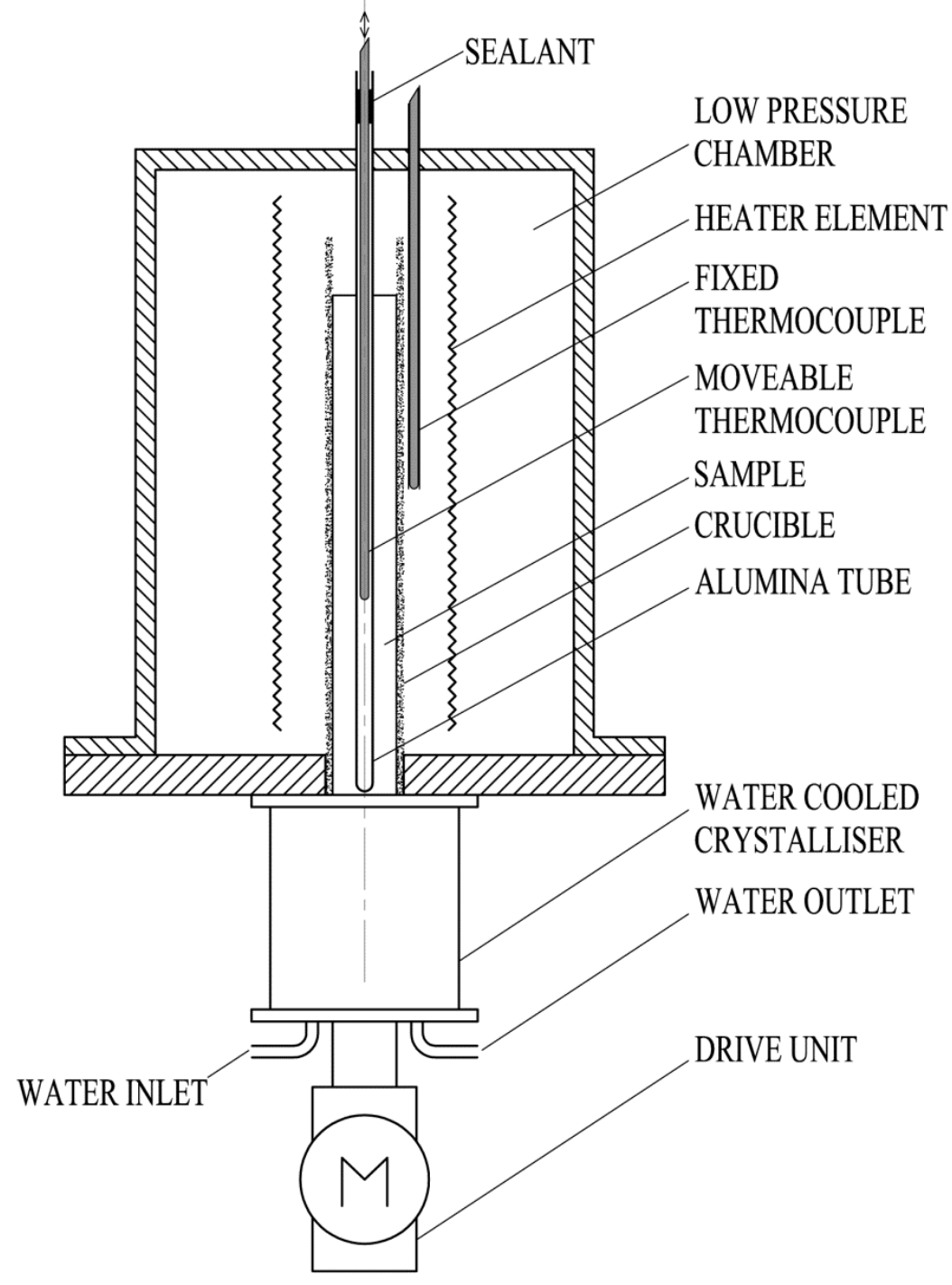

Fig. 2 Schematic of the Bridgman furnace apparatus.

A fixed thermocouple was contained in a protective ceramic tube and positioned at a fixed distance from the crucible wall. The reading from this thermocouple was used to 
control the heater temperature by comparing directly with the heater temperature set-point. The furnace was enclosed in a low pressure chamber so that solidification could occur in a contaminant free and rarefied atmosphere.

\subsubsection{The experimental procedure}

The furnace chamber was evacuated to an absolute pressure of 3Pa and flushed with argon (99.9995\% purity) six times, before being backfilled with argon to an absolute pressure of $10 \mathrm{kPa}$. The hot region heater was set so that the fixed thermocouple read $1680^{\circ} \mathrm{C}$ to partially melt the sample, for a period of 20minutes. The crucible and sample were drawn $20 \mathrm{~mm}$ into the cold region of the furnace where they were allowed to find a steady state temperature profile for a period of 5minutes. The moveable thermocouple was located at an initial axial position of $2 \mathrm{~mm}$ from the zero datum position at the bottom of the sample (in the cold zone). The thermocouple was moved upwards along the sample axis, at $2.5 \mathrm{~mm}$ increments, stopping to measure the axial temperature. The final temperature measurement was taken at an axial position of $160 \mathrm{~mm}$ from the zero datum position.

This procedure was repeated for three other heater settings corresponding to a fixed thermocouple reading of $1650^{\circ} \mathrm{C}, 1630^{\circ} \mathrm{C}$ and $1600^{\circ} \mathrm{C}$. The water cooled crystalliser had a constant output water temperature of $17^{\circ} \mathrm{C}$ during all experiments.

\subsection{Mathematical model of the furnace}

A 1-D numerical model of heat flow was developed and applied to the experimental data.

\subsubsection{Heat flow in a moving rod}

Consider a thin cylindrical rod of constant cross sectional area $A$, and radius $r_{2}$, moving at an axial velocity $u$, through the fixed elemental volume of thickness $\Delta l$, in Fig. 3 . The elemental volume is gaining heat radially through its curved surface with heat flux $q_{2}$, and heat is being internally generated due to the release of latent energy from a solidification process. Heat is diffused by conduction at the west and east faces of the elemental volume, with heat fluxes $q_{\text {in }}$ and $q_{\text {out }}$ respectively. Heat is advected into (or out of) the volume due to the mass flow of the rod through the volume.

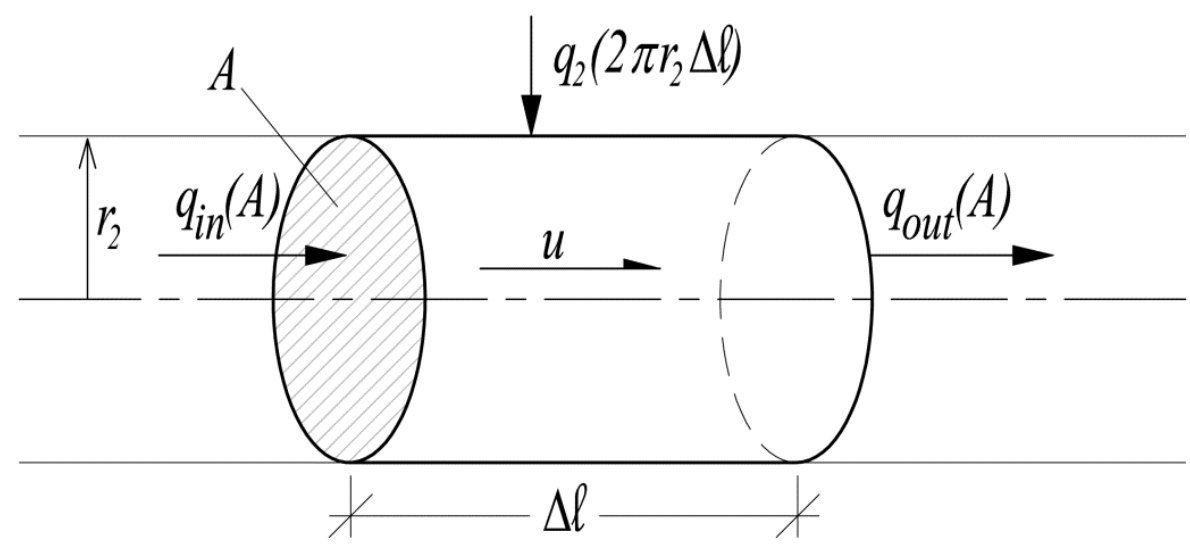

Fig. 3 Conservation of energy in a cylindrical elemental fixed volume. 
This treatment leads to the following one-dimensional heat equation, as adapted from references [17] and [18];

$$
\frac{\partial}{\partial t}(\rho c T)=\frac{\partial}{\partial x}\left(k \frac{\partial T}{\partial x}\right)-\rho c u \frac{\partial T}{\partial x}+\frac{2}{r_{2}} q_{2}+E_{L}
$$

where $\rho, c$ and $k$ are the density, specific heat capacity and thermal conductivity of the rod material. The term on the left hand side of this equation is the time rate of change of sensible energy per unit volume. The first term on the right hand side (RHS) gives the diffusion of thermal energy due to conduction in the axial direction per unit volume. The second term on the RHS is the change of thermal energy of a mass as it moves through space. In other words, it is the difference between the energy advected into and out of the elemental volume. Note that in the experimental procedure outlined in this study, the sample was stationary, i.e., $u=0$, so the advection term is zero. The third term on the RHS deals with heat gained radially per unit volume. The final term on the RHS is the latent heat released due to solidification per unit volume, and is defined as follows;

$$
E_{L}=\frac{\rho L_{M}}{V_{C V}}\left(\frac{\partial V_{s}}{\partial t}\right),
$$

where $V_{C V}$ is the volume of one control volume $(\mathrm{CV}), L_{M}$ is the latent heat of fusion of the alloy per unit mass, and $V_{s}$ is the volume of solid material in a CV. Convection effects, present in liquid parts of the sample, are neglected in this mathematical model.

\subsubsection{Application of the mathematical model to the experiment}

Figure 4 shows a schematic section of the experimental Bridgman furnace apparatus in Fig. 2. The schematic shows the cold (a) and hot (b) regions of the furnace separately. The alumina tube assembly that contained the moveable thermocouple was not considered in this analysis. It was assumed that the effect of the presence of the alumina tube assembly was negligible at very high temperatures, so that $T_{1}$ is equal to the temperature measured by the movable thermocouple.

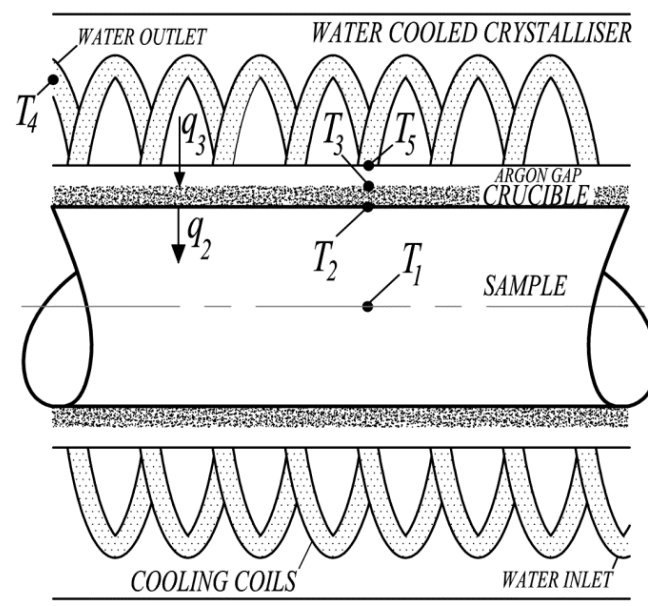

(a)

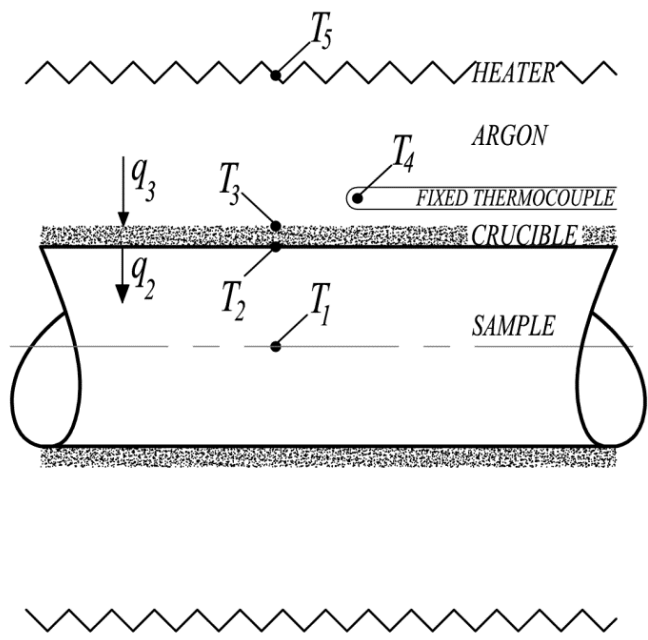

(b)

Fig. 4 Schematic of the cold (a) and hot (b) regions of the Bridgman furnace apparatus. 
The temperature throughout the sample was assumed to vary in the axial direction only - that is, the temperature at the centre of the sample $T_{l}$ was assumed to be equal to the temperature of the sample at the sample-crucible boundary, $T_{2}$.

The sample experiences a heat flux $q_{2}$ at the sample-crucible boundary, in the hot and cold regions of the furnace. The crucible wall was treated as a thermal resistance between the sample surface and the outside surface of the crucible such that $T_{2} \neq T_{3}$. In the hot region of the furnace $T_{3}$ is greater than $T_{2}$, and vice-versa in the cold region. It was assumed that heat transfer in the crucible occurs by conduction in the radial direction only, and that the contact resistance between the sample and the crucible inner wall was negligible. Then, by conservation of radial heat flow and assuming no axial heat flow in the crucible, the radial heat flux at the outside of the crucible $q_{3}$, is related to the radial heat flux at the samplecrucible boundary $q_{2}$, such that;

$$
q_{3} r_{3}=q_{2} r_{2}
$$

where $r_{2}$ is the radius of the sample and $r_{3}$ is the outside radius of the crucible.

The temperature at the crucible wall $T_{3}$ is a function of the ratio of the outer to inner radii of the crucible $r_{3} / r_{2}$, the thermal conductivity of the crucible material $k_{c r u}$ and the radial heat flux $q_{2}$ [19], and is given by;

$$
T_{3}=T_{2}+q_{2} r_{2} \frac{1}{k_{c r u}} \ln \left(\frac{r_{3}}{r_{2}}\right) \text {. }
$$

\subsubsection{The heat transfer coefficients}

Figure 4 (a) shows the cold region of the furnace - the crystalliser component - where the water temperature at the outlet of the crystalliser is $T_{4}$. The heat transfer coefficient at the circumference of the crucible, as a function of axial position in the crystalliser, is then given by;

$$
h_{3}=q_{3} \frac{1}{T_{4}-T_{3}}=q_{2}\left(\frac{r_{2}}{r_{3}}\right) \frac{1}{T_{4}-T_{3}} .
$$

Within the hot region of the furnace, referring to Fig. 4 (b), the theoretical heat transfer coefficient at the crucible circumference would be linearly approximated by the net radial heat flux $q_{3}$, divided by the temperature difference between the surfaces exchanging thermal radiation, $T_{5}-T_{3}$ [20]. However, in our case the heater temperature $T_{5}$ is unknown. Instead we use the known temperature $T_{4}$ (as measured by the fixed thermocouple) to define a heat transfer coefficient at the crucible wall $h_{3}$ for the hot zone, according to Eq. (6).

Similarly, the heat transfer coefficient for heat transferred through the top or bottom face of the sample, $h_{x}$, is given by;

$$
h_{x}=q_{x} \frac{1}{T_{4}-T_{x}}
$$

where $q_{x}$ and $T_{x}$ are the net axial heat flux and the temperature, respectively, at the sample ends: $x=0$ and $x=\ell$, see Fig. 5. 


\subsection{Numerical implementation of the mathematical model}

A numerical method to solve the mathematical model is presented in detail.

\subsubsection{Model domain}

A simple one-dimensional numerical domain, as applied to the sample only, within the experimental setup, is shown in Fig. 5. Note the orientation change in this figure when referring back to Fig. 2 - the $x$-direction relates to the vertical axis of the sample in the furnace. The numerical domain is in the range $0<x<$. The cold region is given by $0<x<x_{1}$, the baffle region is given by $x_{1}<x<x_{2}$ and the hot region given by $x_{2}<x<\ell$. The domain is divided into disc shaped volumes of thickness $\Delta x$. The mush-liquid interface (the front) is shown in the domain given by a front marker $(\mathbf{x})$.

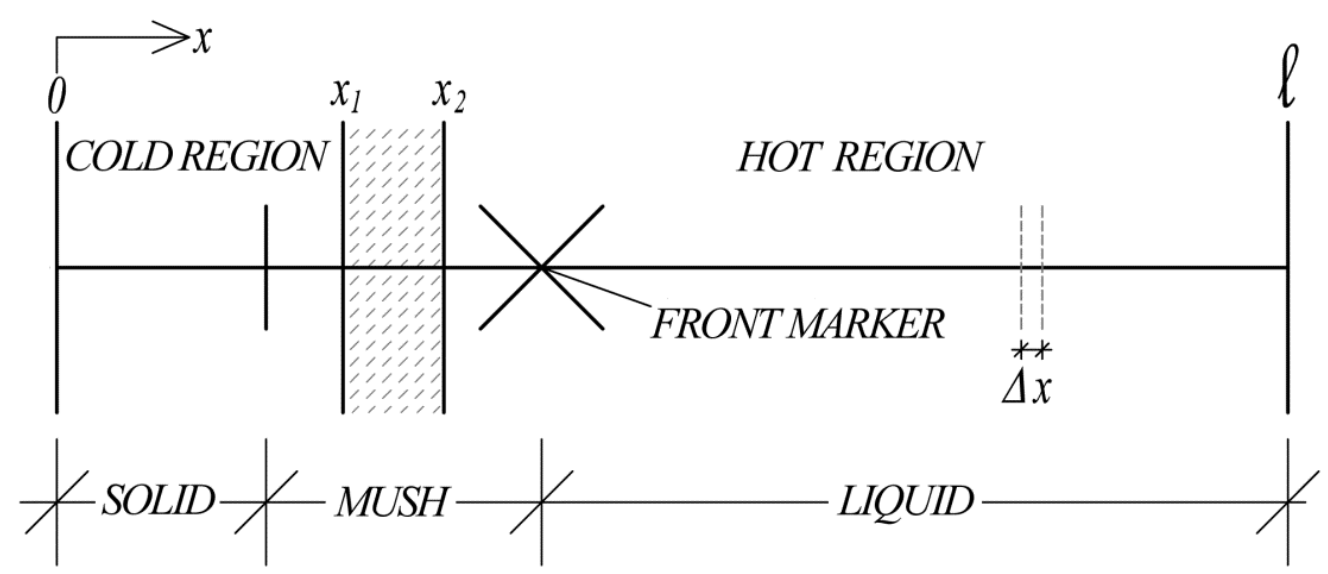

Fig. 5 A one dimensional numerical domain applied to the sample in the experimental set up.

\subsubsection{Discretisation of the heat equation}

The location of the front marker in Fig. 5 is determined using the Bridgman furnace front tracking model (BFFTM), as set out by Mooney et al. [21]. In this model the heat equation is solved by an explicit finite difference control volume $(\mathrm{CV})$ method, where the domain is fixed in space. Application of the BFFTM to the mathematical model, in section 2.2, gives a discretised version of Eq. (2) written as a sum of heat fluxes;

$$
\frac{\rho c \Delta x}{\Delta t}\left(T_{i}^{m+1}-T_{i}^{m}\right)=q_{i-1}+q_{i+1}+q_{a d v}+\Delta x \frac{2}{r_{2}} q_{2}+q_{a}+q_{t},
$$

where $T_{i-1}$ and $T_{i+1}$ are the temperatures of the CVs on the west and east sides of the CV labelled ' $i$ ' in Fig. 6, and the superscripts ' $m$ ' and ' $m+1$ ' refer to the present and future temporal locations in the algorithm. The term in parenthesis is the temperature change at any $\mathrm{CV}$ during one time step $\Delta t$.

The heat fluxes due to thermal diffusion across the west and east faces of a CV (in Fig. 6) are given by $q_{i-1}$ and $q_{i+1}$, respectively, and are calculated as follows; 


$$
\begin{gathered}
q_{i-1}=k\left(\frac{T_{i-1}^{m}-T_{i}^{m}}{\Delta x}\right), \\
q_{i+1}=k\left(\frac{T_{i+1}^{m}-T_{i}^{m}}{\Delta x}\right) .
\end{gathered}
$$

The advection heat flux is $q_{a d v}$ (equal to zero in all experiments here) and $q_{2}$ is the radial heat flux at the circumference of a CV surrounded by the crucible.

Equation (3) is expanded and discretised, as per the front tracking model (FTM) of McFadden and Browne [22], to give the latent heat flux terms; $q_{a}$ and $q_{t}$. Given that the volume of solid, $V_{s}$, is equal to the captured volume of mush, $d$, multiplied by the volumetric fraction of solid, $g_{s}$, i.e., $V_{s}=g_{s} d$, then we get; $\partial V_{s} / \partial t=g_{s}(\partial d / \partial t)+d\left(\partial g_{s} / \partial t\right)$. By discretising the derivative terms and substituting into Eq. (3) we get; $E_{L}=\left(q_{a}+q_{t}\right) / \Delta x$, where;

$$
\begin{aligned}
q_{a} & =\frac{\rho L_{M}}{V_{C V}} g_{s}^{m}\left(\frac{d^{m+1}-d^{m}}{\Delta t}\right) \Delta x, \\
q_{t} & =\frac{\rho L_{M}}{V_{C V}} d^{m}\left(\frac{g_{s}^{m+1}-g_{s}^{m}}{\Delta t}\right) \Delta x .
\end{aligned}
$$

The subscripts ' $a$ ' and ' $t$ ' refer to the advancement of the front, and thickening of the mush behind the front, respectively.

When the front marker ( $x$ ) is in a CV, as shown in Fig. 6, the captured volume of mush in that $\mathrm{CV}$ is given by the volume $d$, and the position of the marker is given by the distance $d / A$, where $A$ is the cross sectional area of the $\mathrm{CV}$.

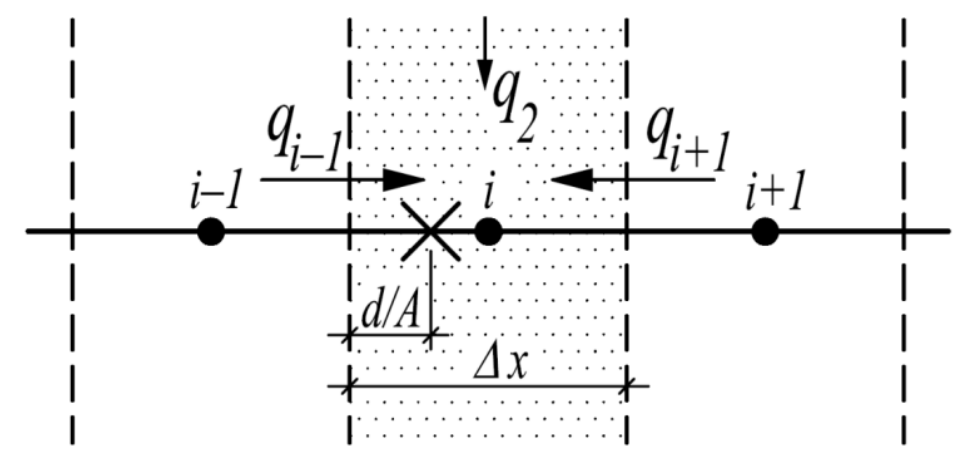

Fig. 6 A typical control volume ' $i$ '.

\subsubsection{Boundary conditions}

A Neumann boundary condition was applied at both ends of the numerical domain. The temperature profile from each experiment was extrapolated using the pchip command in Matlab ${ }^{\circledR}$ [23] to estimate the temperature gradient at $x=0$ and at $x=\ell$. This permitted a 
simple calculation for the diffusion heat flux (in the axial direction only) by application of Fourier's law at both ends of the domain, such that;

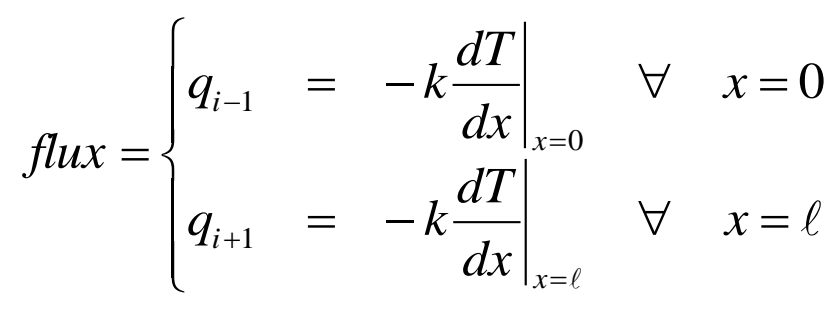

\subsubsection{PID method for solving the inverse heat transfer problem}

An inverse heat transfer problem is one where a thermal effect is known and the cause is discovered [24]. In our case we know the temperature at the centre of the sample (the effect) and we wish to know the heat flux at the surface of the sample (the cause). Various procedures involving iterative matrix calculations exist [25] [26] to solve the inverse heat transfer problem for relatively simple heat equations. However, computational effort is substantially increased for non-linear problems [27] like the one presented in this paper.

An alternative, non-traditional method for solving the inverse heat transfer problem is to manipulate the heat flux $q_{2}$ in a controlled manner, based on the error between the experimentally measured temperature, and the same temperature as simulated by a numerical procedure. This method has been implemented in a similar manner previously by McFadden et al. [28] to estimate heat flux at a heat sink during a directional solidification experiment using a proportional integral derivative (PID) control algorithm.

Figure 7 shows a control system block diagram with negative feedback, applied on a per CV basis, where 'PID' refers to a discrete PID controller process and 'BFFTM' is the process that solves Eq. (8) for $T_{i}{ }^{m+1}$. Given some starting value for the heat flux at the surface of the sample $q_{2}$, the BFFTM can simulate the corresponding CV temperature $T_{1(\text { sim.). }}$. This temperature is fed back and compared with the experimental temperature measurement $T_{1(\text { exp. }}$ and an error signal is generated. The PID controller uses the error signal to continuously and dynamically manipulate the value of $q_{2}$ so that the error value is minimised and a steady state temperature output is reached. At this point the simulated temperature is equal to the experimental sample temperature. This process is carried out at each CV independently.

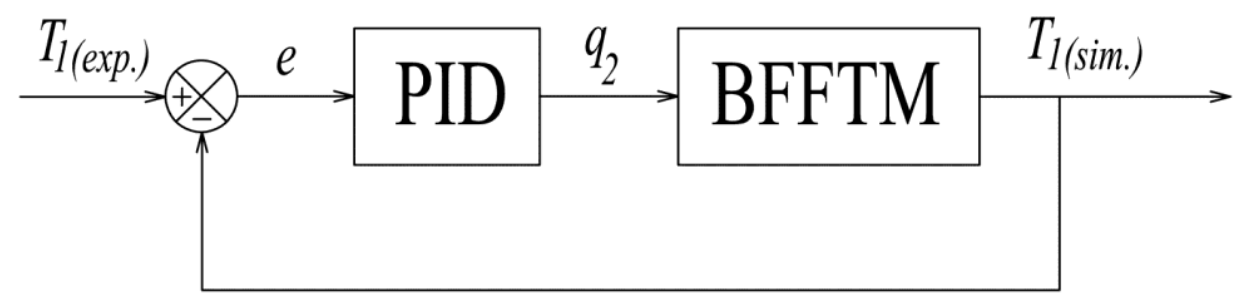

Fig. 7 Control system block diagram with negative feedback loop to control CV temperature.

An ideal PID controller with filtered derivative is used to implement the discrete PID controller process. The control equation - written in the Laplace domain [29] - is given by; 


$$
q_{2}(s)=e(s) K_{c}\left(1+\frac{1}{\tau_{I} s}+\frac{\tau_{D} s}{\frac{\tau_{D}}{N} s+1}\right),
$$

and is illustrated in Fig. 8, where $K_{c}$ is the controller gain, $\tau_{I}$ is the integral time constant, $\tau_{D}$ is the derivative time constant. The controller includes an adjustment variable $N$ for the break frequency of the low pass filter in the derivative term.

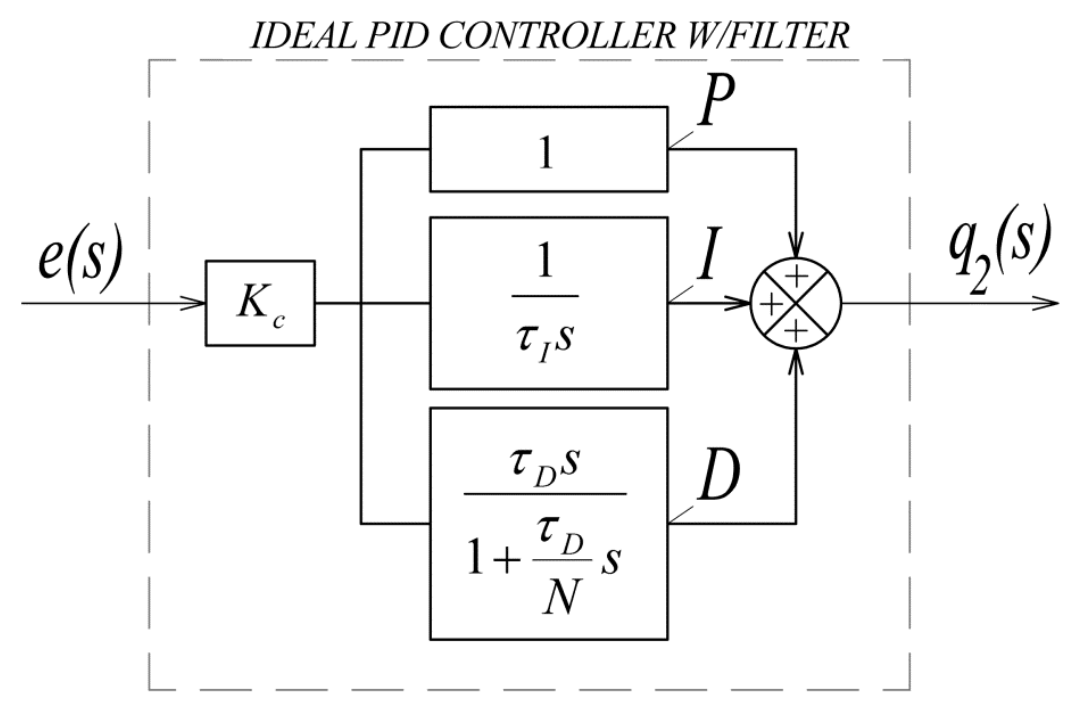

Fig. 8 Ideal PID controller with derivative filter.

Taking the proportional $(P)$, integral $(I)$ and filtered derivative $(D)$ signals individually, we can rewrite each signal in the continuous time domain,

$$
\begin{gathered}
P=K_{c} e(t) \\
I=\frac{K_{c}}{\tau_{I}} \int e(t) d t \\
D=K_{c} \tau_{D}\left(\frac{d e}{d t}\right)-\frac{\tau_{D}}{N}\left(\frac{d D}{d t}\right) .
\end{gathered}
$$

These equations were discretised - for implementation in series with the BFFTM algorithm using a forward difference approximation in the derivative signal and the trapezoidal rule in the integral signal, yielding;

$$
\begin{gathered}
P^{m+1}=K e^{m+1}, \\
I^{m+1}=I^{m}+\frac{K}{\tau_{I}} \Delta t\left(\frac{e^{m+1}+e^{m}}{2}\right), \\
D^{m+1}=\left(1-\frac{N}{\tau_{D}} \Delta t\right) D^{m}+K_{c} N\left(e^{m+1}-e^{m}\right) .
\end{gathered}
$$




\subsubsection{Determining the heat transfer coefficient at the crucible circumference}

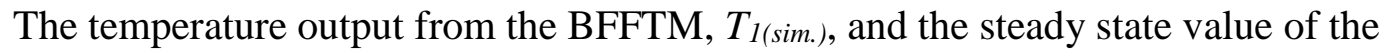
controller manipulated variable $q_{2}$, can be used to calculate the temperature at the exposed side of the crucible $T_{3}$ using Eq. (5), given that $T_{2}=T_{1}$. This allows us to calculate the heat transfer coefficient $h_{3}$ via Eq. (6), as illustrated in the block diagram in Fig. 9.

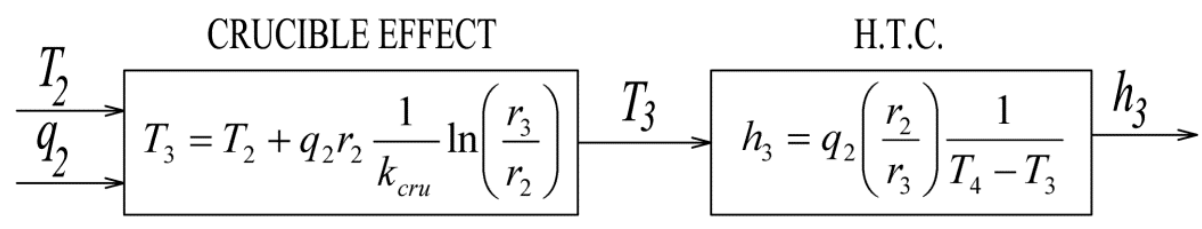

Fig. 9 Block diagram for the calculation of the heat transfer coefficient, $h_{3}$.

\section{Simulation input parameters}

\subsection{Geometrical properties}

The geometrical properties used in the numerical procedure are given in Table 1.

Table 1 Geometrical properties used in all simulations.

\begin{tabular}{ll}
\hline Property & Value \\
\hline Sample length, $\ell[\mathrm{mm}]$ & 170 \\
Baffle zone start, $x_{1}[\mathrm{~mm}]$ & 20 \\
Baffle zone end, $x_{2}[\mathrm{~mm}]$ & 27 \\
Sample radius, $r_{2}[\mathrm{~mm}]$ & 5 \\
Crucible outer radius, $r_{3}[\mathrm{~mm}]$ & 7.5 \\
\hline
\end{tabular}

\subsection{Numerical parameters}

The numerical parameters used in all simulations are given in Table 2. The numerical time step $\Delta t$, and control volume thickness $\Delta x$, were selected so that the explicit finite difference scheme was stable. Convergence of the model was tested by carrying out trial simulations with the inverse heat transfer controller switched off. The trials demonstrated a suitably convergent result using these numerical parameters.

Table 2 Numerical parameters used in all simulations.

\begin{tabular}{ll}
\hline Property & Value \\
\hline Control volume thickness, $\Delta x[\mathrm{~mm}]$ & 0.2 \\
Time step, $\Delta t[\mathrm{~s}]$ & $7.5 \times 10^{-4}$ \\
Number of control volumes & 850 \\
\hline
\end{tabular}




\subsection{Controller parameters}

The discrete PID controller was tuned using the Ziegler Nichols ultimate cycle method [30]. Table 3 shows the resulting values for controller gain $K_{c}$, integral time $\tau_{l}$, and derivative time $\tau_{D}$ used in all simulations.

Table 3 Ideal PID controller settings for all simulations.

\begin{tabular}{ll}
\hline Controller setting & Value \\
\hline Controller gain, $K_{c}$ & 2 \\
Integral time, $\tau_{I}[\mathrm{~s}]$ & 8 \\
Derivative time, $\tau_{D}[\mathrm{~s}]$ & 0.12 \\
Filter variable, $N$ & 10 \\
\hline
\end{tabular}

\subsection{Material properties}

\subsubsection{Thermophysical properties}

The density, specific heat capacity and thermal conductivity of the alloy were estimated by first, second and third order polynomial functions of temperature, such that;

$$
\operatorname{property}(T)=a_{3} T^{3}+a_{2} T^{2}+a_{1} T+a_{0},
$$

where the polynomial coefficients were taken from a study by Egry et al. [31] for the ternary Titanium Aluminide alloy, Ti-45.5\% Al-8Nb (at.\%). This alloy is constitutionally very similar to the alloy used in the experiments described here.

Table 4 shows the polynomial coefficients used to calculate these properties, where $\alpha$ is the thermal diffusivity $(\mathrm{k} / \rho c)$ and $L_{M}=3.4 \times 10^{5}[\mathrm{~J} / \mathrm{kg}]$ is the latent heat of fusion per unit mass. The thermal conductivity of the yttrium oxide crucible was estimated by a second order polynomial function of temperature fitted to data from Touloukian [32], the coefficients of which are shown in the final column of Table 4.

For a given $\mathrm{CV}$, the algorithm calculates the variable property value based on the temperature of that CV at the previous time step. According to Özışık [33] this method of lagging properties by one time step is appropriate for non-linear problems.

Table 4 Polynomial coefficients used to estimate thermophysical properties of the sample alloy and crucible adapted from Egry [31] and Touloukian [32].

\begin{tabular}{|c|c|c|c|c|c|c|}
\hline & \multicolumn{5}{|c|}{ Sample Alloy } & \multirow{3}{*}{$\begin{array}{c}\text { Crucible } \\
\text { Thermal } \\
\text { conductivity, } k_{c r u} \\
{\left[\mathrm{~W} / \mathrm{m} \cdot{ }^{\circ} \mathrm{C}\right]}\end{array}$} \\
\hline & \multicolumn{2}{|c|}{$\begin{array}{c}\text { Specific heat capacity, } c \\
{\left[\mathrm{~J} / \mathrm{kg} \cdot{ }^{\circ} \mathrm{C}\right]}\end{array}$} & \multicolumn{2}{|c|}{$\begin{array}{c}\text { Density, } \rho \\
{\left[\mathrm{kg} / \mathrm{m}^{3}\right]}\end{array}$} & $\begin{array}{c}\text { Thermal } \\
\text { diffusivity, } \alpha \\
{\left[\mathrm{m}^{2} / \mathrm{s}\right]}\end{array}$ & \\
\hline & (liquid) & (solid) & (liquid) & (solid) & (liquid or solid) & \\
\hline$a_{0}$ & 1040 & 632.4 & 4215 & 3133 & $5.36 \times 10^{-6}$ & 21.31 \\
\hline$a_{1}$ & 0 & $7.4 \times 10^{-2}$ & -0.295 & -0.457 & $5.18 \times 10^{-9}$ & -0.020855 \\
\hline$a_{2}$ & 0 & $-2.1 \times 10^{-4}$ & 0 & 0 & $4.3 \times 10^{-13}$ & $5.83 \times 10^{-6}$ \\
\hline$a_{3}$ & 0 & $2.9 \times 10^{-7}$ & 0 & 0 & $-3.01 \times 10^{-15}$ & 0 \\
\hline
\end{tabular}




\subsubsection{Dendrite kinetics}

The growth velocity $v$, of the front marker $(x)$ during solidification was calculated in the BFFTM using a suitable dendritic growth law taken from a study by Rebow et al. [34] as;

$$
v=2.63 \times 10^{-6} \Delta T^{2.79},
$$

where $\Delta T$ is the undercooling at the front, i.e., the difference between the temperature at the front marker and the equilibrium liquidus temperature for the alloy.

\subsubsection{Solid fraction estimation}

The BFFTM model requires knowledge of the volumetric fraction of solid $g_{s}$, as a function of temperature. Solid regions have a solid fraction of unity; liquid regions have a solid fraction of zero; while mushy regions have some value in between unity and zero, depending on the temperature and the composition. The CALPHAD (CALculation of PHAse Diagrams) method uses validated thermodynamic databases for each of the alloy elements to estimate the Gibbs free energy, and hence phase diagram, for that alloy [6]. Thermocalc ${ }^{\circledR}$ [35] used the CALPHAD method to determine a function for solid fraction in terms of temperature. Figure 10 shows the resulting solid fraction to temperature relationship for the alloy used in the experiments here. The equilibrium solidus temperature $T_{s}=1434^{\circ} \mathrm{C}$ and the equilibrium liquidus temperature $T_{l}=1550^{\circ} \mathrm{C}$ were taken from this data set as the temperatures corresponding to a solid fraction of unity and zero respectively. The data was generated using the 'Modified Scheil Module' based on the approach of Chen and Sundman [36]. The model assumed Scheil type solidification [37], that is, no diffusion in solid; however, equilibrium back diffusion of the interstitial alloy elements (boron and carbon) was permitted.

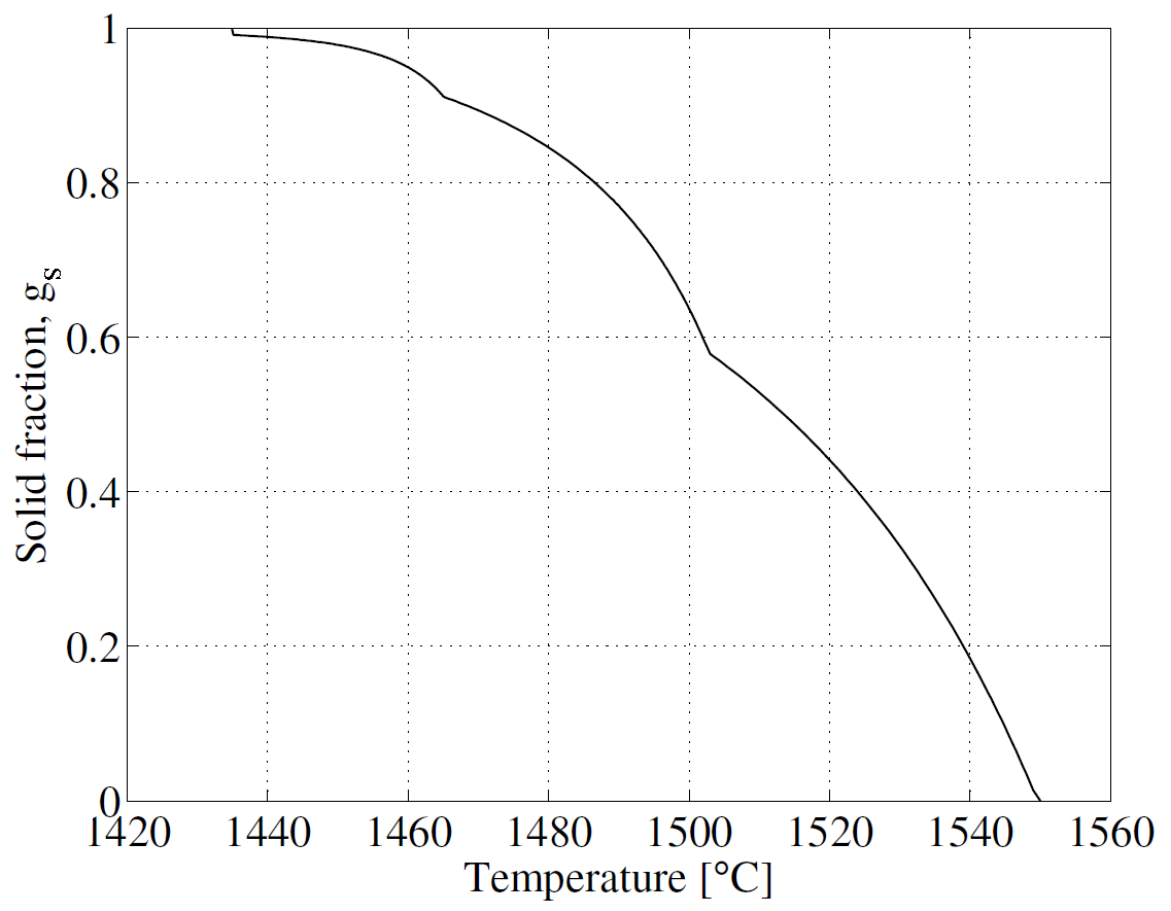

Fig. 10 Solid fraction to temperature relationship for Ti-44.5Al-4.5Nb-0.2C-0.2B (at.\%) as estimated using Thermocalc ${ }^{\circledR}[35]$ via the 'Modified Scheil Module'. 


\section{Results}

In this section the results have been categorised into experimental and numerical results. The reference numbers for each of the experiment are given in Table 5. Note that in the cold region of the furnace $T_{4}$ refers to the steady state water outlet temperature at the crystalliser, while in the hot region of the furnace $T_{4}$ refers to the steady state temperature measurement at the heater's thermocouple.

Table 5 Experiment reference numbers with hot and cold region reference temperatures.

\begin{tabular}{lcccc}
\hline & \multicolumn{4}{c}{ Experiment Number } \\
& E.1 & E.2 & E.3 & E.4 \\
\hline COLD REGION, $T_{4}\left[{ }^{\circ} \mathrm{C}\right]$ & 17 & 17 & 17 & 17 \\
HOT REGION, $T_{4}\left[{ }^{\circ} \mathrm{C}\right]$ & 1680 & 1650 & 1630 & 1600 \\
\hline
\end{tabular}

\subsection{Experiment results}

Figure 11 shows the axial temperature profiles that were measured for each of the experiments referenced in Table 5.

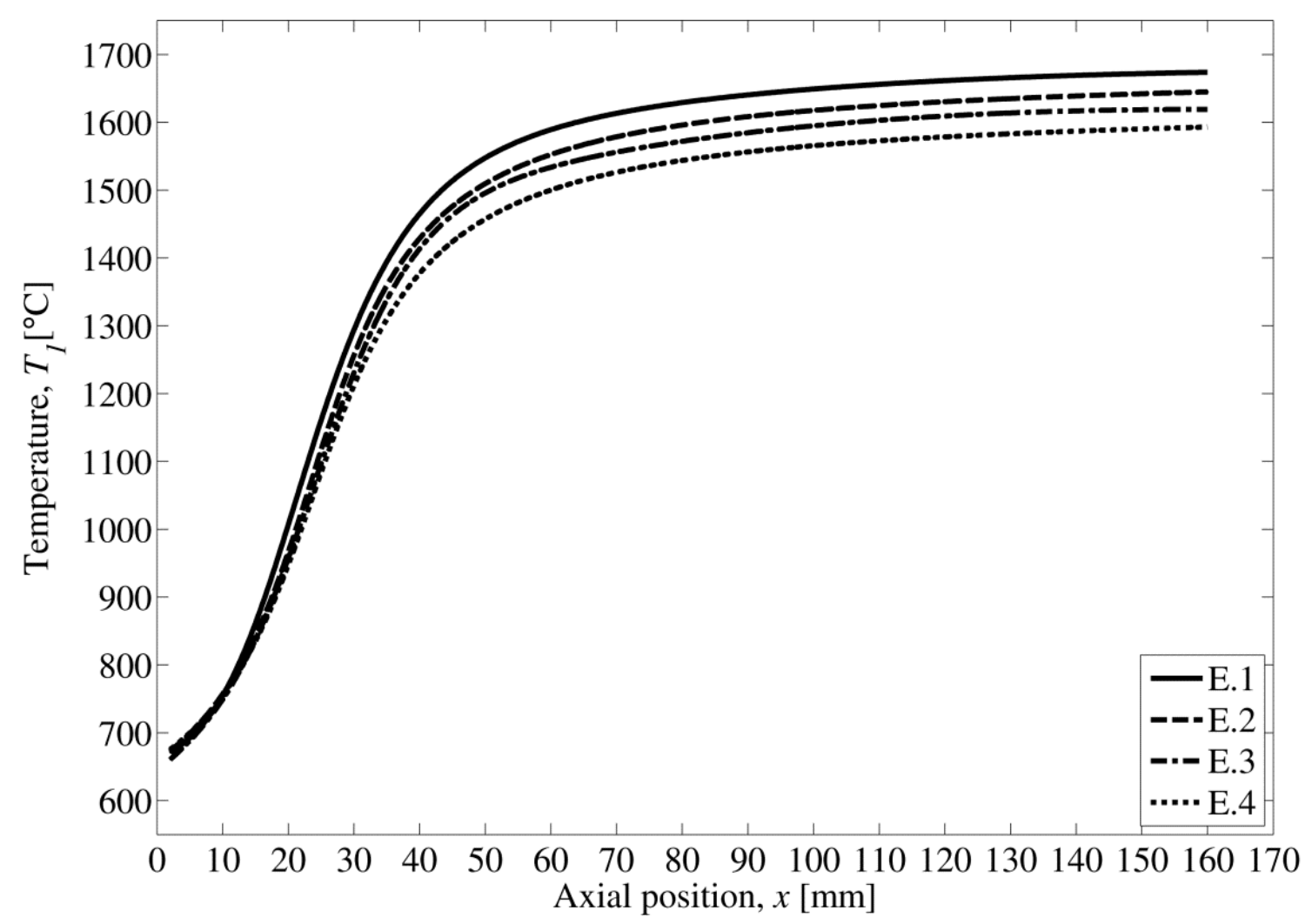

Fig. 11 Experimental temperature profiles at four different heater settings. 


\subsection{Numerically processed results}

\subsubsection{Heat flux and heat transfer coefficients at the domain boundaries}

Table 6 shows the estimated values for the heat flux $q_{x}$, from Eq. (13), and heat transfer coefficient $h_{x}$, from Eq. (7), at the domain boundaries. The temperature at the boundaries, $T_{x}$, is also shown (as extrapolated from the experimental data.)

Table 6 Heat flux, heat transfer coefficients, and extrapolated temperature at the domain boundaries.

\begin{tabular}{ccccccc}
\hline $\begin{array}{c}\text { Experiment } \\
\text { No. }\end{array}$ & $\begin{array}{c}q_{x} \\
{\left[\mathrm{~kW} / \mathrm{m}^{2}\right]}\end{array}$ & $\begin{array}{c}h_{x} \\
{\left[\mathrm{~W} / \mathrm{m}^{2} \cdot{ }^{\circ} \mathrm{C}\right.}\end{array}$ & $\begin{array}{c}T_{x} \\
{\left[{ }^{\circ} \mathrm{C}\right]}\end{array}$ & $\begin{array}{c}q_{x} \\
{\left[\mathrm{~kW} / \mathrm{m}^{2}\right]}\end{array}$ & $\begin{array}{c}h_{x} \\
{\left[\mathrm{~W} / \mathrm{m}^{2} \cdot{ }^{\circ} \mathrm{C}\right]}\end{array}$ & $\begin{array}{c}T_{x} \\
{\left[{ }^{\circ} \mathrm{C}\right]}\end{array}$ \\
\hline E.1 & -96 & 146 & 670.51 & 0.34 & 68 & 1675.00 \\
E.2 & -104 & 161 & 661.92 & 0.87 & 292 & 1647.03 \\
E.3 & -120 & 188 & 653.86 & 0.21 & 20 & 1619.09 \\
E.4 & -101 & 154 & 671.44 & 2.18 & 471 & 1595.37 \\
\hline
\end{tabular}

\subsubsection{Heat flux at the circumference of the sample}

Figure 12 shows the heat flux at the circumference of the sample $q_{2}$ - as simulated by the PID controller for each experiment - plotted as a function of axial position. The average heat flux for all the experiments is also shown. 


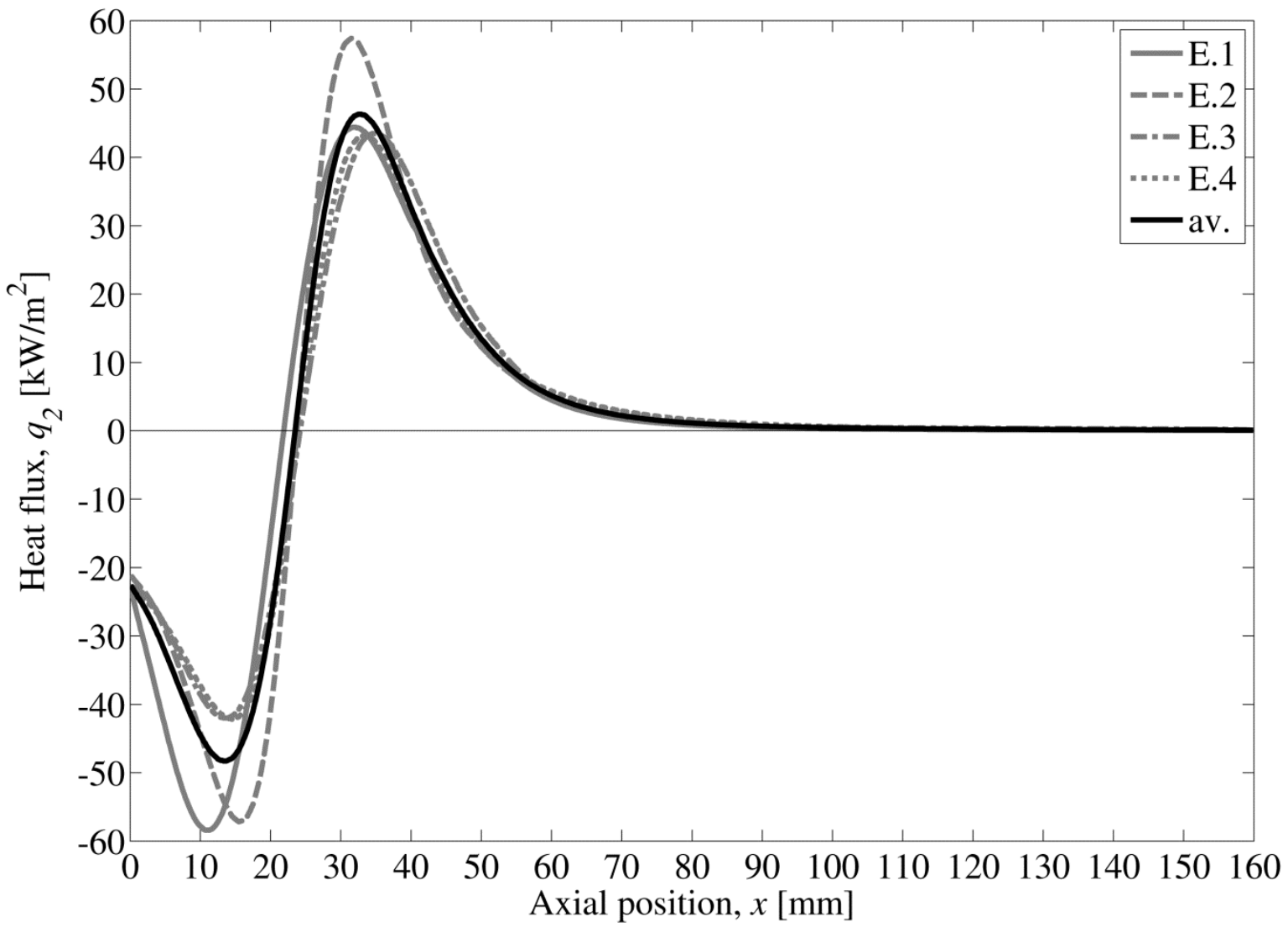

Fig. 12 Heat flux at the sample circumference versus axial position.

\subsubsection{Heat transfer coefficient at the circumference of the crucible}

Figure 13 shows the resulting heat transfer coefficient $h_{3}$ as a function of axial position for each experiment. The average heat transfer coefficient as a function of axial position is also shown. 


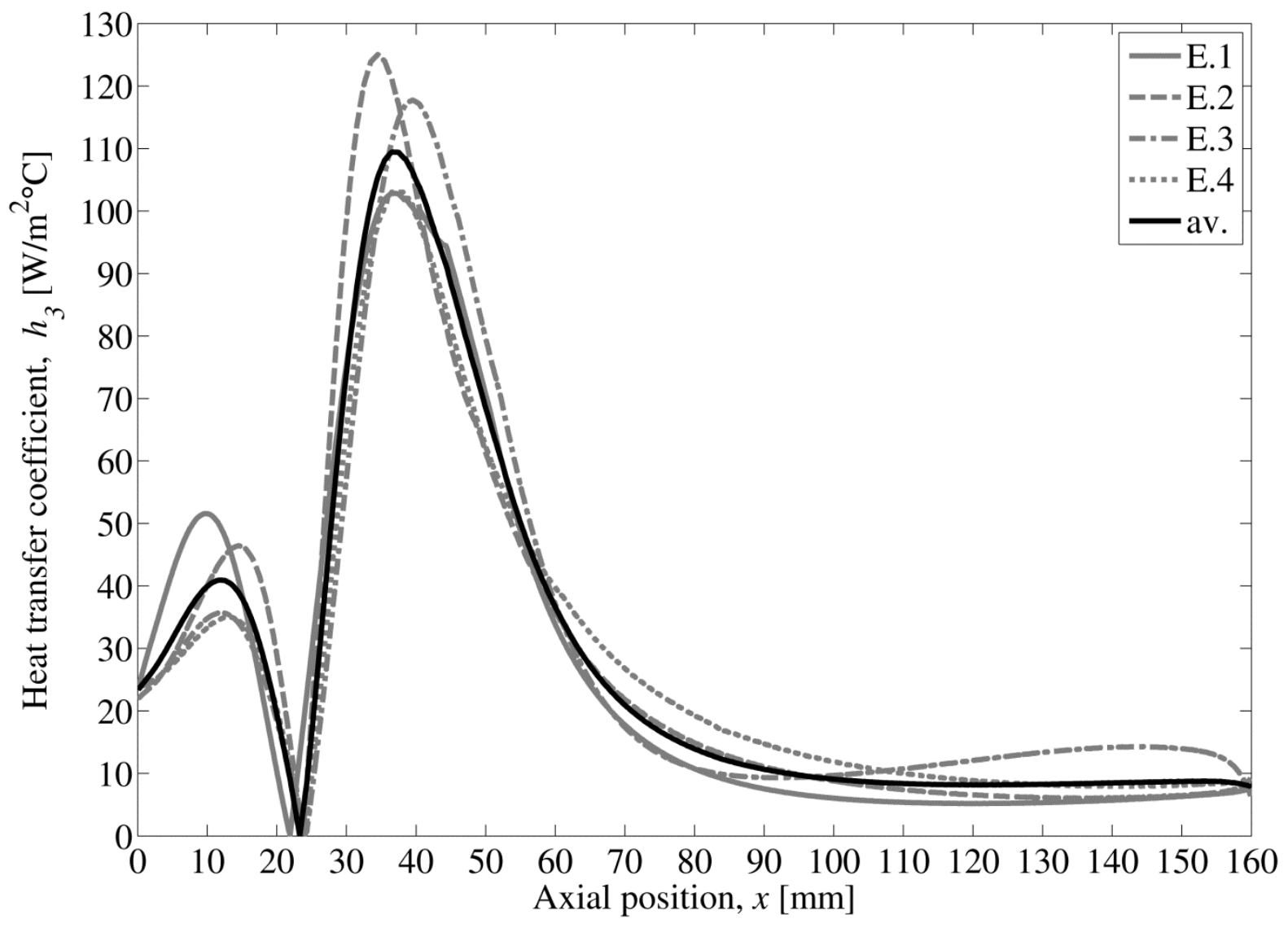

Fig. 13 Heat transfer coefficient at the crucible circumference versus axial position.

\section{Discussion}

\subsection{Discussion of results}

\subsubsection{Experiment results}

Figure 11 shows the measured temperature profile for each experiment, where the only difference between the experimental trials is that the furnace set point temperature is changed in accordance with Table 5. Experimental trial E.1 had the highest heater setting $\left(1680^{\circ} \mathrm{C}\right)$ and E. 4 had the lowest heater setting $\left(1600^{\circ} \mathrm{C}\right)$. As the heater settings were lowered the temperature profiles in the hot region lowered proportionally. However, in the cold region the temperature profiles were convergent to each other. This was to be expected given that the outflow temperature from the water cooled crystalliser was held constant during experiments.

\subsubsection{Heat flux and heat transfer coefficients at the domain boundaries}

Table 6 shows that the heat flux at the cold end of the domain $(x=0)$ was much larger than that observed at the hot end $(x=\ell)$. This was to be expected as the temperature gradient was much higher at the cold end of the sample than at the hot end. The estimated heat transfer 
coefficients at the cold end of the sample were similar in each experiment and in the range $146 \mathrm{~W} / \mathrm{m}^{2 \circ} \mathrm{C}$ to $188 \mathrm{~W} / \mathrm{m}^{2 \circ} \mathrm{C}$.

Heat flux in the axial direction at the hot end of the sample ranged from $0.21 \mathrm{~kW} / \mathrm{m}^{2}$ to $2.18 \mathrm{~kW} / \mathrm{m}^{2}$. These heat fluxes are very small compared to the axial heat fluxes at the cold end, ranging from $-96 \mathrm{~kW} / \mathrm{m}^{2}$ to $-120 \mathrm{~kW} / \mathrm{m}^{2}$. The extrapolation exercise at the hot end of the sample is more sensitive than at the cold end. Consequently, the hot end axial temperature gradients (and hence heat fluxes and heat transfer coefficients) estimation shows greater variance than that of the cold end.

Additionally, in relation to the hot end, it should be noted that the temperature at $x=\ell$ (from the extrapolated curve) is not equal to the heater reference temperature in each case, i.e., the profile does not reach the heater temperature. If the temperature profile did reach the heater temperature we might expect a very large $h_{x}$ at $x=\ell$. Note, for example, in E. 1 how $T_{x}$ at $x=\ell$ is $5^{\circ} \mathrm{C}$ below the heater reference temperature $\left(T_{4}=1680^{\circ} \mathrm{C}\right)$. This explains the magnitude and difference in values of the heat transfer coefficient at the hot end, since $h_{x}=q_{x} /\left(T_{4}-T_{x}\right)$.

It should be noted that other authors [12] have neglected the heat flux at the hot end of the sample where the sample is relatively 'long and thin', having a length-to-diameter ratio of 12.5 (17 in our study). Alternatively, in other studies [28][38], and in a similar manner to our approach, a small nominal value for the heat flux at the hot end $q_{x}$ is set as a fixed value during simulations.

Finally, note that using our model, the heat flux at the hot end of the sample has a minimal effect on the radial heat flux predictions in Fig. 12. At the cold end, however, the situation is different; the relatively large axial heat flux condition has a greater influence on the radial heat flux at $x=0$.

\subsubsection{Heat flux at the circumference of the sample}

In Fig. 12 we see that the heat flux at the sample circumference in the cold zone is negative. This means that the controller extracted heat from the CVs in this region. Similarly, the heat flux at the sample circumference in the hot region is always positive, that is, the controller added heat to $\mathrm{CVs}$ here. The transition from negative to positive heat flux occurred in the baffle region of the furnace. The transition from cold to hot zone (where the heat flux is zero) is therefore an adiabatic location. This result is cognisant with a simpler mathematical analysis. Rewriting Eq. (2) as a steady state equation (removing the transient terms) gives,

$$
\frac{\partial}{\partial x}\left(k \frac{\partial T}{\partial x}\right)=-\frac{2}{r_{2}} q_{2}
$$

If the radial heat flux $q_{2}$ is zero for an adiabatic condition then the RHS of this equation is also zero. Hence, mathematically, any adiabatic location should correspond with a point of inflection in the temperature profile, i.e., the second derivative of temperature with respect to axial position. It can be shown that all of the temperature profiles in Fig. 11 share points of inflection in the vicinity of the baffle zone in the experimental apparatus. In Bridgman furnace terminology the baffle zone is sometimes called the adiabatic zone. The approach 
used here has independently confirmed the existence of the adiabatic condition within the baffle region.

It should be noted that a direct solution for Eq. (23) is difficult to obtain because of the non-linear nature of the problem and the inherent numerical difficulties with differentiating noisy experimental data. The problem is non-linear because thermal conductivity is a function of temperature and solid fraction. The approach adopted here, which is based on an integrative algorithm, is an optimal method for achieving the aims and objectives.

\subsubsection{Heat transfer coefficient at the circumference of the crucible}

The method presented here estimated heat transfer coefficients using known reference temperatures in the heater and the crystalliser. For the heater system, the thermocouple for controlling the hot zone temperature was used to provide the reference temperature. Ideally, the surface temperature of the heater would have been used as the reference temperature; however, it is typical in high-temperature furnace designs to control the heater with a thermocouple in the vicinity of the heater which is not on the surface itself. This practical solution was deemed necessary and sufficient for future use. For the crystalliser, the reference temperature is simply the temperature of the water at the outlet of the crystalliser. This temperature was regulated throughout the experiments.

As discussed earlier with Eq. (1) and by Rosch et al. [10], the magnitude of the furnace heat transfer coefficient (at the crucible circumference) should increase in proportion to a function temperature cubed. However, this behaviour is not clearly apparent in the results presented here. In our particular case, the most significant change in the heat transfer conditions was observed along the axial direction. It is proposed that this feature is specific to the furnace used and may be due to the narrow operating conditions, i.e., for a heater setting in the range: $1600^{\circ} \mathrm{C}$ to $1680^{\circ} \mathrm{C}$. Additional experiments over a wider range of temperatures are required to confirm any dependence on the heater's temperature setting.

Following on from the findings, it was possible to take the data from the results and develop an average value for the heat flux at the sample circumference and the heat transfer coefficient at the crucible circumference at each axial location. The averaged results are provided in Fig. 12 and Fig. 13. The averaged values could be applied to other scenarios providing that they are within a suitable range of the operating parameters. This application is demonstrated next.

\subsubsection{Average heat transfer coefficient at the circumference of the crucible}

For demonstration purposes, the average heat transfer coefficient curve given in Fig. 13 was applied to independent simulation runs for each of the experimental trials. The PID controller was removed from the model; hence the simulations were direct calculations with no error correction. Fig. 14 shows the resulting steady state temperature profiles. It is clear that there is close agreement between experimental and simulated data. The level of agreement is better in the hot zone of the furnace than in the cold zone. 


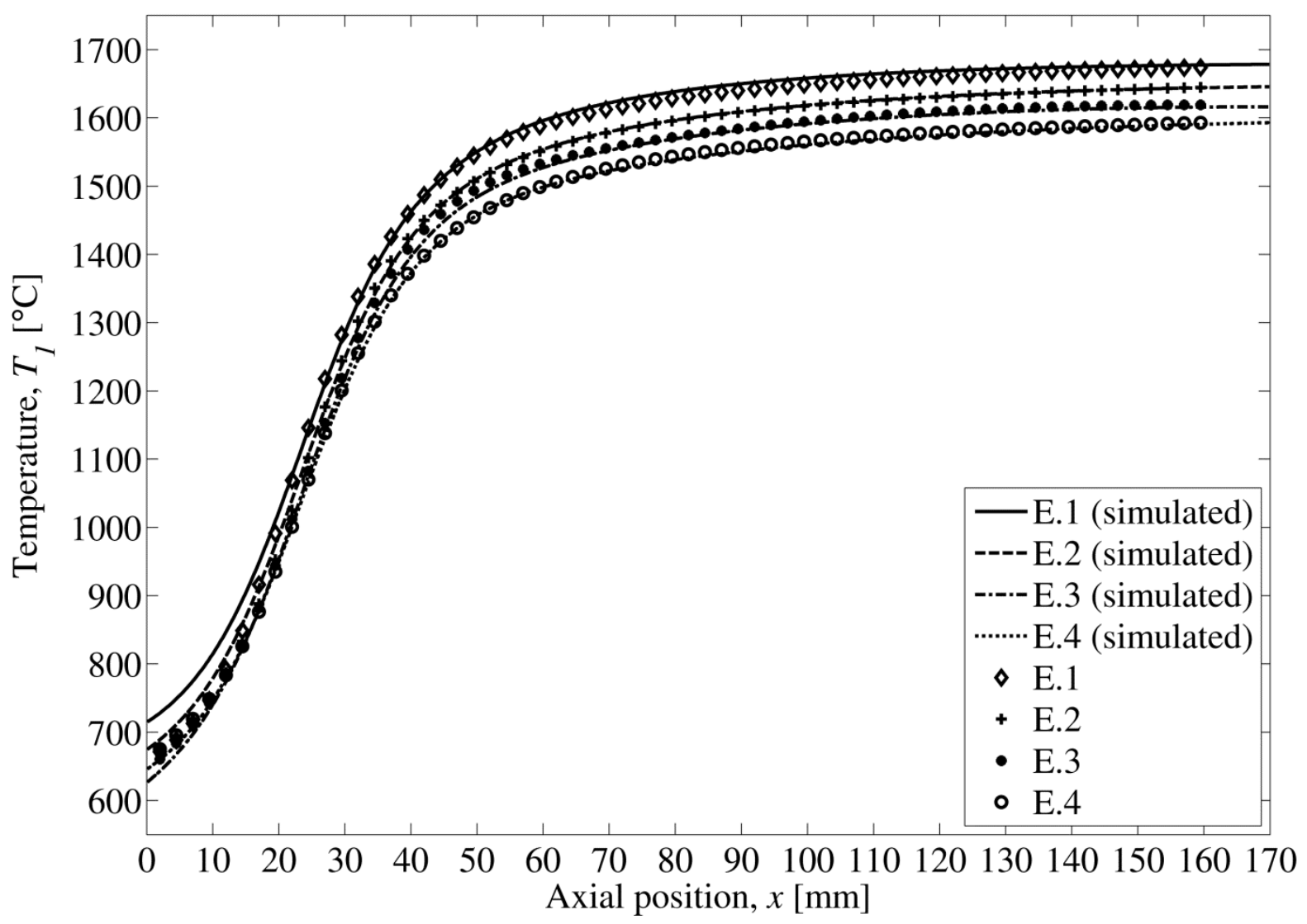

Fig. 14 Experimental and simulated temperature profiles using the average heat transfer coefficient.

\subsection{Discussion of the 1-dimensional heat flow assumption}

It was assumed that a one dimensional model for heat flow in the sample was reasonable for this problem. The Biot number, Bi, can be used to vindicate this assumption [18]. It is calculated as follows;

$$
B i=\frac{h L_{c}}{k}
$$

where $h$ is the heat transfer coefficient at the surface of a body, $L_{c}$ is the characteristic length of the body, and $k$ is the thermal conductivity of the body material. For a rod the characteristic length is equal to half its radius. The Biot number relates the thermal resistance to heat flow at the surface of a body, to the thermal resistance within that body. When $B i<0.1$ it can be assumed that the temperature at the centre of that body is very nearly equal to the temperature at the surface [39].

In our case, the heat transfer coefficient used to calculate the Biot number should be taken referenced to the sample radius at $r_{2}$. This heat transfer coefficient $h_{2}$ can be calculated by combining the thermal resistance of the crucible and the thermal resistance at the exposed side of the crucible wall, as per the method used by Fu et al. [40], as follows; 


$$
\frac{1}{h_{2} r_{2}}=\frac{\ln \left(r_{3} / r_{2}\right)}{k_{c r u}}+\frac{1}{h_{3} r_{3}} .
$$

From the results in Fig. 13 we see a maximum value - across all simulations - for $h_{3}=125 \mathrm{~W} / \mathrm{m}^{2} \cdot{ }^{\circ} \mathrm{C}$, occurring in experiment E. 2 at $x=34.5 \mathrm{~mm}$. The resulting maximum heat transfer coefficient at the surface of the sample is then $h_{2}=170 \mathrm{~W} / \mathrm{m}^{2} \cdot{ }^{\circ} \mathrm{C}$. Using $h_{2}$ to calculate the corresponding maximum Biot number we get $B i=0.03$. This being the worst case scenario, the one dimensional heat flow assumption is justified.

\subsection{Discussion on convection in the liquid}

Using the BFFTM, thermo-solutal convection in the molten alloy and in mush regions is neglected for the following reasons. Firstly, in our experiment the sample is stationary, i.e., $u=0$, and the sample is allowed to settle for 5 minutes before measurements are taken. This is important in respect of solutal convection. For our alloy, when $u>0$, the primary component rejected at the interface during solidification is aluminium (44.5 at.\%) having a partition coefficient of approximately $k_{\text {part }}=0.9$. Since aluminium has a lower density than titanium, the aluminium rich liquid at the interface can become hydrostatically unstable during growth, leading to convection in the melt [41]. The secondary alloy component to consider is niobium (4.5 at.\%) having a partition coefficient of approximately $k_{\text {part }}=1.1$. This may also cause a destabilising effect on the melt. The partitioning of aluminium and niobium at the interface is a dynamic effect only present when $u>0$. In any case, it should be noted that, since $k_{\text {par }} \approx 1$ for both aluminium and niobium, the partitioning is weak. We assume that any solutal convection - induced during the growth part of the experiment - has dissipated during the settling period of 5 minutes before the experimental measurements are taken.

Secondly, in a vertical Bridgman furnace scenario the thermal gradient is parallel with the gravity vector. Given that our alloy has a lower density at higher temperatures, the axial temperature gradient has a stabilising effect on convection in the melt. In addition, we assume that the sample is isothermal in the radial direction.

Where it is required to model the solidification of a multicomponent alloy, and the destabilising effects of convection in the liquid are to be accounted for, a suitable model should be considered such as the one demonstrated by Anderson et al. [42].

\subsection{Discussion on heat flow in the crucible}

We have assumed that heat flow in the crucible occurs in steady state and in the radial direction only. However, it is probable that some axial heat flow occurs in the crucible. This assumption may introduce some error into the calculation of the heat transfer coefficient at the circumference of the crucible. If we divide the crucible into annular volumes of thickness $\Delta x$, internal radius $r_{2}$, and external radius $r_{3}$, we can perform a qualitative heat balance exercise.

The value for $q_{2}$ is fixed by the PID controller so that the experimental and simulated temperatures match. From the point of view of the annular crucible volume, $q_{2}$ is negative as it is heat leaving the annular volume for the sample, and $q_{3}$ is positive as it is heat entering the 
annular volume. If some net axial heat flow were to occur in the crucible, the value for $q_{3}$ would have to change accordingly, so that $q_{2}$ is maintained.

While our approach for predicting the heat transfer coefficient across the crucible does have potential for error - in respect of axial heat flow - we note that the method is consistent with other authors [40] for similar crucible geometries.

\section{Conclusion}

Firstly, the aims and objectives of the work have been met;

1. The heat flux at both ends of the sample was estimated.

2. The heat transfer coefficient at both ends of the sample was estimated.

3. The heat flux at the circumference of the sample as a function of axial position was estimated using a combined experimental-numerical approach.

4. The heat transfer coefficient at the circumference of the crucible was estimated as a function of axial position.

The method presented here estimated heat transfer coefficients using known reference temperatures in the heater and the crystalliser regions of the furnace. The resulting heat transfer coefficients can be used as benchmark input data for simulating other experiments that were performed using the same furnace, within similar operating conditions.

From a wider perspective, the approach used is useful to experimentalists and modellers, where the temperature of the furnace heater surface (or heat sink surface) $T_{5}$ is known. In this case, the radiation heat transfer coefficients in the hot region of the furnace can be estimated, a task that is normally quite difficult due to uncertainty in values for the spectral emissivity of the surfaces exchanging heat. The method of using a PID controller for this purpose has not been previously reported in a Bridgman furnace analysis.

The usefulness of the method was demonstrated by re-running each simulation with the PID controller removed from the model. The average heat transfer coefficient curve was used to calculate the heat flux at the circumference of the sample. The resulting simulated temperature profiles closely matched the experimental data.

Finally, the main assumptions of the method used are discussed; 1-dimensional heat flow in the sample, negligible convection effects in the liquid parts of the sample, and no axial heat flow in the crucible.

\section{Acknowledgements}

This work was carried out as part of the GRADECET (GRAvity DEpendance of Columnar to Equiaxed Transition in Ti-Al Alloys) research project. The authors R.P. Mooney and S. McFadden would like to acknowledge the financial support of the European Space Agency PRODEX programme (contract number 4000107132 ) and the managerial support of the Irish Delegation to ESA within Enterprise Ireland. The authors J. Lapin and Z. Gabalcová would like to acknowledge the financial support of the Slovak Research and Development Agency 
under the contract APVV-0434-10, the Slovak Grant Agency for Science under the contract VEGA 2/0149/13 and the Slovak Academy of Sciences under the contract of MVTS funding of ESA project GRADECET. Finally, gratitude is expressed to Ulrike Hecht and Victor Witusiewicz of ACCESS e.V. for providing CALPHAD and Thermocalc data.

\section{Nomenclature}

$A$

$B i$

$c$

$D$

$d$

$e$

$g_{s}$

$h$

I

$k$

$k_{\text {part }}$

$K_{c}$

$L_{A}$

$L_{M}$

$L_{c}$

$\ell$

$N$

$P$

$q$

$r$

$t$

$T$

$u$

$v$

$V_{C V}$

$x$

$\alpha$

$\tau_{D}$

$\Delta l$

$\Delta t$

$\Delta x$

$\rho$

\section{Sub/Super-scripts}

1

2 sample cross sectional area $\left[\mathrm{m}^{2}\right]$

Biot number [-]

specific heat capacity at constant pressure $\left[\mathrm{J} / \mathrm{kg} \cdot{ }^{\circ} \mathrm{C}\right]$

derivative controller signal [-]

captured volume of mush in a control volume $\left[\mathrm{m}^{3}\right]$

error $\left[{ }^{\circ} \mathrm{C}\right]$

volumetric fraction of solid [-]

heat transfer coefficient $\left[\mathrm{W} / \mathrm{m}^{2} \cdot{ }^{\circ} \mathrm{C}\right]$

integral controller signal [-]

thermal conductivity $\left[\mathrm{W} / \mathrm{m} \cdot{ }^{\circ} \mathrm{C}\right]$

partition coefficient [-]

controller gain [-]

baffle thickness [mm]

latent heat of fusion per unit mass $[\mathrm{J} / \mathrm{kg}]$

characteristic length [mm]

sample length [mm]

low pass filter variable [-]

proportional controller signal [-]

heat flux $\left[\mathrm{kW} / \mathrm{m}^{2}\right]$

radius $[\mathrm{mm}]$

time [s]

temperature $\left[{ }^{\circ} \mathrm{C}\right]$

pulling velocity $[\mathrm{m} / \mathrm{s}]$

columnar dendrite tip velocity $[\mathrm{m} / \mathrm{s}]$

volume of one control volume $\left[\mathrm{m}^{3}\right]$

axial position [mm]

thermal diffusivity $\left[\mathrm{m}^{2} / \mathrm{s}\right]$

derivative time constant [s]

integral time constant [s]

elemental volume thickness [mm]

numerical time step [s]

control volume thickness [mm]

density $\left[\mathrm{kg} / \mathrm{m}^{3}\right]$

at the sample axis

at the sample crucible boundary 


$\begin{array}{ll}3 & \text { at the exposed crucible wall } \\ 4 & \text { at a reference position } \\ 5 & \text { at the heater (or crystalliser) surface } \\ a & \text { advancement } \\ a d v & \text { advection } \\ c r u & \text { crucible } \\ \text { exp } & \text { experimental } \\ i & \text { spatial label } \\ L & \text { latent } \\ l & \text { liquidus } \\ m & \text { temporal label } \\ s & \text { solidus } \\ \text { sim } & \text { simulated } \\ t & \text { thickening } \\ x & \text { axial direction }\end{array}$

\section{References}

[1] P. W. Bridgman, "Certain physical properties of single crystals of tungsten, antimony, bismuth, tellurium, cadmium, zinc and tin," Proc. Am. Acad. Arts Sci., vol. 60, p. 303, 1925.

[2] D. C. Stockbarger, "The production of large single crystals of lithium fluoride," Rev. Sci. Instrum., vol. 7, no. 3, pp. 133-136, 1936.

[3] K. Shi, J. Liu, and W.-Q. Lu, "Numerical investigation of the interfacial characteristics during Bridgman growth of compound crystals," Appl. Therm. Eng., vol. 27, no. 1112, pp. 1960-1966, Aug. 2007.

[4] A. Kermanpur, N. Varahraam, E. Engilehei, P. Mohammadzadeh, and M. Davami, "Directional solidification of Ni base superalloy IN738LC to improve creep properties," Mater. Sci. Technol., vol. 16, no. 5, pp. 579-586, 2000.

[5] W. Kurz and D. J. Fisher, Fundamentals of solidification. Aedermannsdorf: Trans Tech Publications, 1986.

[6] J. A. Dantzig and M. Rappaz, Solidification, First ed. Lausanne: EPFL Press, 2009.

[7] D. J. Jarvis and D. Voss, "IMPRESS Integrated Project-An overview paper," Mater. Sci. Eng. A, vol. 413-414, pp. 583-591, Dec. 2005.

[8] F. Lemoisson, S. McFadden, M. Rebow, D. J. Browne, L. Froyen, D. Voss, D. J. Jarvis, A. V. Kartavykh, S. Rex, W. Herfs, D. Groethe, J. Lapin, O. Budenkova, J. Etay, and Y. Fautrelle, "The Development of a Microgravity Experiment Involving Columnar to Equiaxed Transition for Solidification of a Ti-Al Based Alloy," Mater. Sci. Forum, vol. 649, pp. 17-22, May 2010.

[9] M. Banan, R. T. Gray, and W. R. Wilcox, "An experimental approach to determine the heat transfer coefficient in directional solidification furnaces," J. Cryst. Growth, vol. 113, no. 3-4, pp. 557-565, 1991.

[10] W. Rosch, W. Jesser, W. Debnam, A. Fripp, G. Woodell, and T. K. Pendergrass, "A technique for measuring the heat transfer coefficient inside a Bridgman furnace," $J$. Cryst. Growth, vol. 128, no. 1-4 part 2, pp. 1187-1192, 1993.

[11] W. Rosch, A. Fripp, W. Debnam, and T. K. Pendergrass, "Heat transfer measurements in the Bridgman configuration," J. Cryst. Growth, vol. 137, no. 1-2, pp. 54-58, 1994. 
[12] D. M. L. Bartholomew and A. Hellawell, "Changes of growth conditions in the vertical Bridgman-Stockbarger method for the solidification of aluminum," J. Cryst. Growth, vol. 50, no. 2, pp. 453-460, Oct. 1980.

[13] C. E. Chang and W. R. Wilcox, "Control of interface shape in the vertical bridgmanstockbarger technique," J. Cryst. Growth, vol. 21, no. 1, pp. 135-140, 1974.

[14] S. Sen and W. R. Wilcox, "Influence of crucible on interface shape, position and sensitivity in the vertical Bridgman-Stockbarger technique," J. Cryst. Growth, vol. 28, no. 1, pp. 36-40, Jan. 1975.

[15] P. C. Sukanek, "Deviation of freezing rate from translation rate in the BridgmanStockbarger technique I. Very low translation rates," J. Cryst. Growth, vol. 58, no. 1, pp. 208-218, Jun. 1982.

[16] J. Lapin and Z. Gabalcová, "Solidification behaviour of TiAl-based alloys studied by directional solidification technique," Intermetallics, vol. 19, no. 6, pp. 797-804, Jun. 2011.

[17] H. S. Carslaw and J. C. Jaeger, Conduction of Heat in Solids, Second ed. London: Oxford University Press, 1959.

[18] A. Bejan, Heat Transfer, 1st ed. New York: John Wiley \& Sons, 1993.

[19] J. M. Kay and R.M. Nedderman, Fluid mechanics and transfer processes. Cambridge University Press, 1985.

[20] H. R. N. Jones, Radiation heat transfer. Oxford University Press, 2000.

[21] R. P. Mooney, S. McFadden, M. Rebow, and D. J. Browne, "A Front Tracking Model for Transient Solidification of $\mathrm{Al}-7 \mathrm{wt} \% \mathrm{Si}$ in a Bridgman Furnace," Trans. Indian Inst. Met., vol. 65, no. 6, pp. 527-530, 2012.

[22] S. McFadden and D. J. Browne, "A front-tracking model to predict solidification macrostructures and columnar to equiaxed transitions in alloy castings," Appl. Math. Model., vol. 33, no. 3, pp. 1397-1416, Mar. 2009.

[23] MathWorks, "Piecewise Cubic Hermite Interpolating Polynomial (PCHIP)." [Online]. Available: http://www.mathworks.co.uk/help/matlab/ref/pchip.html. [Accessed: 16Aug-2013].

[24] M. N. Özışık and H. R. B. Orlande, Inverse Heat Transfer: Fundamentals and Applications. New York: Taylor \& Francis, 2000.

[25] A. N. Tikhonov and V. Y. Arsenin, Solutions of ill posed problems. Washington, D.C.: Wiley, 1977.

[26] O. M. Alifanov, "Solution of an inverse problem of heat conduction by iteration methods," J. Eng. Phys. Thermophys., vol. 26, no. 4, pp. 471-476, Apr. 1974.

[27] J. V. Beck, B. Blackwell, and C. R. St. Clair Jr., Inverse heat conduction: ill-posed problems. New York: Wiley, 1985.

[28] S. McFadden, D. J. Browne, and C.-A. Gandin, "A Comparison of Columnar-toEquiaxed Transition Prediction Methods Using Simulation of the Growing Columnar Front," Metall. Mater. Trans. A, vol. 40, no. 3, pp. 662-672, Jan. 2009.

[29] D. E. Seborg, D. A. Mellichamp, T. F. Edgar, and F. J. Doyle III, Process Dynamics and Control, 3rd ed. Wiley, 2011.

[30] J. G. Ziegler and N. B. Nichols, "Optimum settings for automatic controllers," Trans. ASME, vol. 64, pp. 759-768, 1942.

[31] I. Egry, R. Brooks, D. Holland-Moritz, R. Novakovic, T. Matsushita, E. Ricci, S. Seetharaman, R. Wunderlich, and D. Jarvis, "Thermophysical Properties of $\gamma$-Titanium Aluminide: The European IMPRESS Project," Int. J. Thermophys., vol. 28, no. 3, pp. 1026-1036, Aug. 2007. 
[32] Y. S. Touloukian, R. W. Powell, C. Y. Ho, and P. G. Klemens, Thermophysical Properties of Matter: Vol 2 Thermal Conductivity Nonmetallic Solids. New YorkWashington: IFI/Plenum, 1970.

[33] M. N. Özış1k, Finite difference methods in heat transfer, 1st ed. Boca Raton: CRC Press, 1994.

[34] M. Rebow, D. J. Browne, and Y. Fautrelle, "Combined Analytical and Numerical Front Tracking Approach to Modeling Directional Solidification of a TiAl-Based Intermetallic Alloy for Design of Microgravity Experiments," Mater. Sci. Forum, vol. 649, pp. 243-248, Aug. 2010.

[35] Thermo-Calc Software AB, "Thermo-Calc 3.0," 2013. [Online]. Available: http://www.thermocalc.com/Thermo-Calc.htm. [Accessed: 26-Feb-2013].

[36] Q. Chen and B. Sundman, "Computation of partial equilibrium solidification with complete interstitial and negligible substitutional solute back diffusion," Mater. Trans. JIM, vol. 43, no. 3, pp. 551-559, 2002.

[37] E. Scheil, "Bemerkungen zur schichtkristallbildungle," Zeitschrift Fur Met., no. 34, pp. 70-72, 1942.

[38] C.-A. Gandin, "From Constrained to Unconstrained Growth During Directional Solidification," Acta Mater., vol. 48, no. 10, pp. 2483-2501, Jun. 2000.

[39] F. P. Incropera, D. P. Dewitt, T. L. Bergman, and A. S. Lavine, Fundamentals of Heat and Mass Transfer, 6th ed. New York: John Wiley \& Sons, 2007.

[40] T.-W. Fu, W. R. Wilcox, and D. J. Larson, "Rate change transients in BridgmanStockbarger growth of MnBi-Bi eutectic," J. Cryst. Growth, vol. 57, no. 1, pp. 189193, 1982.

[41] R. Trivedi, A. Karma, T. S. Lo, P. Mazumder, J. S. Park, and M. Plapp, "Dynamic Pattern Formation in the Two-Phase Region of Peritectic Systems," in 2nd Workshop on Solidification Microstructures, 1998.

[42] D. M. Anderson, G. B. McFadden, S. R. Coriell, and B. T. Murray, "Convective instabilities during the solidification of an ideal ternary alloy in a mushy layer," $J$. Fluid Mech., vol. 647, p. 309, Mar. 2010. 